\title{
HPTLC Studies on the Phenyl Propanoids of Albizia lebbeck Benth
}

\author{
Md. Nazneen Bobby ${ }^{1}$, Wesely EG ${ }^{2}$, Johnson $\mathrm{M}^{* 3}$ \\ ${ }^{1}$ Research \& Development Centre, Bharathiyar University, Coimbatore - 641046. \\ ${ }^{2}$ Department of Botany, Arignar Anna Government Arts College, Namakkal-637002. \\ ${ }^{3}$ Department of Plant Biology and Plant Biotechnology, St. Xavier's College (Autonomous), Palayamkottai, Tamil Nadu, \\ India - 627002.
}

\begin{abstract}
The present study was aimed to find out the phenyl propanoids HPTLC profile of the medicinally important plant Albizia lebbeck Benth. HPTLC studies were carried out following Harborne and Wagner et al. method. The Toluene-ethyl acetate (9.3:0.7) was served as mobile phase for phenyl propanoids. Linear ascending development was carried out in $20 \mathrm{~cm} \times 10 \mathrm{~cm}$ twin trough glass chamber (Camag, Mutenz, Switzerland) saturated with the mobile phase and the chromatoplate development for two times with the same mobile phase to get good resolution of phytochemical contents. The developed plate was sprayed with Vanillin sulphuric acid reagent as spray reagent and dried at $120^{\circ} \mathrm{C}$ in hot air oven for $10 \mathrm{~min}$. The petroleum ether extracts of $A$. lebbeck leaves displayed the presence of 13 types of phenyl propanoids with 13 different $\mathrm{Rf}$ values ranged from 0.02 to 0.92 . The ethyl acetate extract of $A$. lebbeck leaves illustrated the presence of 14 different types of phenyl propanoids with 14 different $\mathrm{Rf}$ values with range from 0.01 to 0.94 . The methanolic extract of A. lebbeck leaves demonstrated the presence of 6 different types of phenyl propanoids with 6 different Rf values. Maximum number (14) of phenyl propanoids has been observed in ethyl acetate extracts and petroleum ether followed by ethyl acetate (13) extracts of A. lebbeck leaves. The results of the present study developed novel phytochemical marker to identify the medicinally important plant. Further advanced spectroscopic and chromatographic studies will lead for the structural elucidation and identification of active components present in the leaves of A. lebbeck.
\end{abstract}

Keywords: Phenyl propanoids, finger print, Phytochemistry

\section{INTRODUCTION}

Beginning in prehistoric times, humans have attempted to treat every known type of illness and malady with naturally occurring products. Such products were initially in their natural state, such as leaves, berries, roots, stems and extracts. With the advance of science and greater understanding of chemistry, humans have been able to produce synthetically and extract a great variety of pharmaceuticals which were previously unknown or unidentified. Recently, the scientific community has taken an increased interest in discovering the various effects of the ancient herbal remedies actually produce. Extensive studies have been conducted into the efficacy of a great number of these products and the results have largely been positive [1-14]. The foremost constraint in the exercise of traditional knowledge as remedies for the diseases is the lack of scientific knowledge on the plants especially on the standardization of raw material, manufacturing process and the final product. To fulfill the lacuna, the phytochemists are focused their research not only for the characterization of the chemical constituents present in the plants; but also focused on the production of phyto-chemical marker for the identification of crude drugs. This will help them to distinguish the adulterant from the medicinal source. A biomarker on the other hand is a group of chemical compounds which are in addition to being unique for that plant material also correlates with biological efficacy. So the necessitate arises to lay standards by which the right material could be selected and incorporated into the formulation. TLC and HPTLC are methods commonly applied for the identification, assay and the testing of purity, stability, dissolution or content uniformity of raw materials (herbal and animal extracts, fermentation mixtures, drugs and excipients) and formulated products (pharmaceuticals, cosmetics, nutrients) [15].

Up to date, a few thousands of different secondary metabolite structures have been identified in plants; the largest of them are the phenyl propanoids (PPs, synonym, phenylethanoids), isoprenoids and alkaloids [16]. By chemical structure, secondary metabolites in plants are divided in several major classes such as: - terpenes (isoprenoids, terpenoids), PPs, phenylpropanoids and their derivatives (flavonoids, tannins, glycosides, and lignins), nitrogen-containing compounds (alkaloids and heterocyclic aromatics) [16]. PPs belong to a large class of plant phenols produced through shikimic acid pathway. Phenolic compounds are plant secondary metabolites that constitute one of the most common and widespread groups of substances in plants [17]. As stated by Harborne [18], the term "phenolic" or "polyphenol" can be precisely defined chemically as a substance which possesses an aromatic ring bearing one (phenol) or more (polyphenol) hydroxyl substituents, including functional derivatives (esters, methyl ethers, glycosides, etc.): as a general rule, the terms phenolics and polyphenols refer to all secondary natural metabolites arising biogenetically from the shikimate-phenylpropanoids-flavonoids pathways, 
producing monomeric and polymeric phenols and polyphenols. Phenylpropanoid metabolism is one of the well known major metabolic pathways stimulated during the hypersensitive response (HR). Phenylpropanoid-based polymers, like lignin, suberin, or condensed tannins, contribute substantially to the stability and robustness of gymnosperms and angiosperms towards mechanical or environmental damage like drought or wounding [19].

Albizia lebbeck Benth is widely distributed in India and is also found in South Africa and Australia. Traditionally, the barks are used in toothache and diseases of the gum. Decoction of the leaves and barks are protective against bronchial asthma and other allergic disorders. Barks and seeds are astringent and are given in piles and diarrhoea. Ethanolic and methanolic extracts of pods possesses anti-protozoal, anti-fertility activity, hypoglycemic and anticancer properties [20-23]. The plant extract is reported to have antiseptic, anti- dysenteric, anti-ovulatory, nootropic, anti-inflammatory, antimicrobial activity and anti-tubercular activities [24-27]. The plant also contains saponins, macrocyclic alkaloids, anthraquinone glycosides, tannins, and flavonols [26]. The saponin constituents of Albizia so far described are echinocystic acid glycosides [28, 29]. The Albizia saponins A, B, and C were isolated from the barks of A. lebbeck [30]. Phytochemical investigations on A. lebbeck pod showed that they contains 3', 5 Dihydroxy 4', 7 dimethoxy flavone and N- Benzoyl L phenyl alaninol [31]. The beans of the plant contain albigenic acid-a new triterpenoid sapogenin [32]. The tri-O-glycoside flavonols kaempferol and quercetin were identified from the leaves of A. lebbeck [33]. Albizia hexoside, a new hexaglycosylated saponin was isolated from leaves of A. lebbeck [34]. Misra et al [35] isolated N-demethyl budmunchiamines from A. lebbeck seeds and Maa et al [36] confirmed the tannin presence in A. lebbeck. Bobby et al. [37] reported the alkaloids HPTLC profile of $A$. lebbeck. With this background the present study was aimed to characterize the phenyl-propanoid profile present in the leaves of $A$. lebbeck by using HPTLC.

\section{MATERIALS AND METHODS}

A. lebbeck was collected from natural habitats, Rasipuram, Nammakkal, Tamil Nadu, India, and authenticated by Dr. E.G. Wesely and the specimens voucher were deposited in the St. Xavier's College Herbarium for further reference. The fresh leaves were shade dried and powdered using the electric homogenizer. The powdered samples were extracted with 150 $\mathrm{ml}$ of petroleum ether, methanol and ethyl acetate for $8-12 \mathrm{~h}$ by using the Soxhlet apparatus. Preliminary phytochemical screening was done by following the standard method described by Harborne [38], HPTLC studies were carried out following Wagner et al. [39]. For the present study CAMAG HPTLC system equipped with Linomat V applicator, TLC scanner 3, Reprostar 3 with 12 bit CCD camera for photo documentation, controlled by WinCATS- 4 software were used. All the solvents used for HPTLC analysis was obtained from MERCK. The samples $(5 \mu \mathrm{l})$ were spotted in the form of bands of width $5 \mathrm{~mm}$ with a Camag microlitre syringe on pre-coated silica gel glass plate $60 \mathrm{~F}-254(20 \times 10 \mathrm{~cm}$ with $250 \mu \mathrm{m}$ thickness (E. Merck, Darmstadt, Germany) using a Camag Linomat IV (Switzerland). The plates were pre-washed by methanol and activated at $60^{\circ} \mathrm{C}$ for 5 min prior to chromatography. The sample loaded plate was kept in TLC twin trough developing chamber (after saturated with Solvent vapor) with respective mobile phase (phwnyl-propanoids) and the plate was developed in the respective mobile phase up to $90 \mathrm{~mm}$. The Toluene-ethyl acetate (9.3:0.7) was employed as mobile phase for phenyl propanoids. Linear ascending development was carried out in $20 \mathrm{~cm}$ x $10 \mathrm{~cm}$ twin trough glass chamber (Camag, Mutenz, Switzerland) saturated with the mobile phase and the chromatoplate development for two times with the same mobile phase to get good resolution of phytochemical contents. The optimized chamber saturation time for mobile phase was $30 \mathrm{~min}$ at room temperature $\left(25 \pm 2^{\circ} \mathrm{C}\right)$. The developed plate was dried by hot air to evaporate solvents from the plate. The developed plate was sprayed with Vanillin sulphuric acid reagent as spray reagent and dried at $120^{\circ} \mathrm{C}$ in hot air oven for $10 \mathrm{~min}$. The plate was photo-documented at UV $366 \mathrm{~nm}$ and daylight using Photo-documentation (CAMAG REPROSTAR 3) chamber. Finally, the plate was fixed in scanner stage and scanning was done at $366 \mathrm{~nm}$. The plate was kept in Photo-documentation chamber (CAMAG REPROSTAR3) and captured the images under White light, UV light at 254 and $366 \mathrm{~nm}$. Densitometric scanning was performed on Camag TLC scanner III and operated by CATS software (V 3.15, Camag). Violet colored zone at day light mode was present in the petroleum ether track, it was observed from the chromatogram after derivatization, which confirmed the presence of phenyl propanoid in the given sample.

\section{RESULTS}

Various mixtures of the mobile phase were employed for HPTLC analysis in order to obtain high resolution and reproducible peaks for the phenyl propanoids of A. lebbeck leaves. The mixtures consists of Toluene- Chloroform- acetone (4: 2.5: 3.5) produced high resolution and more number of reproducible peaks for the phenyl propanoids of A. lebbeck leaves. The results of present study confirmed that the mixtures of Toluene- Chloroform- acetone (4: $2.5: 3.5)$ as the mobile phase for the phenyl propanoids of A. lebbeck leaves (Fig. 1A - 1D). The petroleum ether extracts of A. lebbeck leaves displayed the presence of 13 types of phenyl propanoids with 13 different Rf values ranged from 0.02 to 0.92 (Table - 1). Of which two (Rf. 0.48 and 0.83 ) were identified as phenyl propanoids, others were unknown. The ethyl acetate extract of $A$. lebbeck leaves illustrated 
the presence of 14 different types of phenyl propanoids with 14 different Rf values with range from 0.01 to 0.94 (Table - 2). The methanolic extract of $A$. lebbeck leaves demonstrated the presence of 6 different types of phenyl propanoids with 6 different Rf values $0.02,0.18,0.32,0.34,0.76$ and 0.94 (Table - 3). Maximum number (14) of phenyl propanoids has been observed in ethyl acetate extracts and petroleum ether followed by ethyl acetate (13) extracts of the leaves of $A$. lebbeck. HPTLC chromatogram of the phenyl propanoids (Table - 4) of A. lebbeck leaves are illustrated in Fig. 1E - 1K.

\section{DISCUSSION}

To a large extent, secondary metabolites derive from three biosynthetic routes, namely the phenyl propanoid, isoprenoid and alkaloid pathways. Phytochemicals arising from these pathways include not only compounds with a broad-spectrum antibiotic activity, but also powerful antioxidants able to counteract oxidative stress [40-42]. Plants need phenolic compounds for pigmentation, growth, reproduction, resistance to pathogens and for many other functions. Many of plant-derived phenolic compounds (flavonoids, isoflavonoids, coumarines, and lignans) are secondary products of PPs metabolism [43-44]. Phenyl propanoids belong to the largest group of secondary metabolites produced by plants, mainly in response to biotic or abiotic stresses such as infections, wounding, UV irradiation, exposure to ozone, pollutants and other hostile environmental conditions [16]. Plant-derived phenyl propanoids (PPs) and their derivatives are among the most common biologically active components of food, spices, aromas, fragrances, propolis, wines, essential oils, beer and traditional medicine. Taking into account numerous defensive roles of PPs and their derivatives in plants, these compounds are of great interest, especially for medicinal use as antioxidant, UV screens, anticancer, anti-virus, anti-inflammatory, wound healing, and antibacterial agents $[16,45]$. Plant natural products derived from phenylalanine and the phenyl propanoid pathways are impressive in their chemical diversity and are the result of plant evolution, which has selected for the acquisition of large repertoires of pigments, structural and defensive compounds, all derived from a phenyl propanoid backbone via the plantspecific phenyl propanoid pathway [46]. These compounds are important in plant growth, development and responses to environmental stresses and thus can have large impacts on agricultural productivity. While plant-based medicines containing phenyl propanoid-derived active components have long been used by humans, the benefits of specific flavonoids and other phenyl propanoid-derived compounds to human health and their potential for long-term health benefits have only been recognized more recently. In the present study we observed the known phenyl propanoids presence in the petroleum ether extracts leaves of $A$. lebbeck. The methanolic and ethyl acetate extracts also showed the unknown phenyl propanoids presence in leaves of A. lebbeck. Rahul et al [26] observed that A. lebbeck contains saponins, macrocyclic alkaloids, anthraquinone glycosides, tannins, and flavonols and antimicrobial activity. The results of the present study confirm Rahul et al observations and supplement to the phytochemical observations on A. lebbeck [26]. Decoction of the A. lebbeck leaves and barks are protective against bronchial asthma and other allergic disorders. The plant extract is reported to have antiseptic, anti- dysenteric, anti-ovulatory, nootropic, anti-inflammatory, and anti-tubercular activities [24-27]. The HPTLC phenyl propanoids profile studies substantiate the earlier observations on A. lebbeck.

Chromatographic fingerprint has been suggested to be practical and comprehensive approach for identifying authenticity and evaluating the quality, consistency and the stability of raw herbal materials and herbal extracts. HPTLC is a valuable tool for reliable identification because it can provide chromatographic fingerprints that can be visualized and stored as electronic images [47-53]. These flexible and cost-effective techniques present the advantage of the simultaneous processing of standards and samples with versatile detection possibilities, including a great variety of post-chromatographic derivatisation reagents [54-56].

\section{CONCLUSION}

The results of the present study also confirmed and substantiated the previous observations on the HPTLC studies on the medicinally important plants. The results of the present study developed novel phytochemical marker to identify the medicinally important plant. Further advanced spectroscopic and chromatographic studies will lead for the structural elucidation and identification of active components present in the leaves of A. lebbeck. 


\section{REFERENCES}

1. M. Johnson, M. Maridass, and V. Irudayaraj, Preliminary Phytochemical and Antibacterial Studies on Passiflora edulis, Ethnobotanical Leaflets, 12, 2008, 425-432.

2. M. Johnson, E.G. Wesely, M.S. Kavitha, and V. Uma, Antibacterial activity of leaves and inter-nodal callus extracts of Mentha arvensis L, Asian Pacific Journal of Tropical Medicine, 4(3), 2011, 196-200.

3. M. Johnson, A. Babu, and V. Irudayaraj, Antibacterial Studies on In Vitro Derived Calli of Ocimum basilicum L, J. Chem. Pharm. Res., 3(1), 2011, 715-720.

4. K. Paul Raj, V. Irudayaraj, M. Johnson, and D. Patric Raja, Phytochemical and anti-bacterial activity of epidermal glands extract of Christella parasitica (L.) H. Lev. Asian Pacific Journal of Tropical Biomedicine, 1(1), 2011, 8-11.

5. C. Karpagavinayagam, V. Irudayaraj, and M. Johnson, Preliminary survey on herbivory in south Indian ferns, J. Basic \& Applied Biol., 4(1\&2), 2010, 137-143.

6. V. Irudayaraj, M. Janaky, M. Johnson, and N. Selvan, Preliminary Phytochemical and Antimicrobial Studies on a Spike-Moss Selaginella inaequalifolia (Hook. \& Grev.) Spring, Asian Pacific Journal of Tropical Medicine, 2010, 957-960.

7. P. Selvamaleeswaran, E.G. Wesely, M. Johnson, S. Velusamy, and N. Jeyakumar, The effect of leaves extracts of Clitoria ternatea Linn. against the fish pathogens, Asian Pacific Journal of Tropical Medicine, 3(9), 2010, 723-726.

8. D. Haripriya, N. Selvan, N. Jeyakumar, R. Periasamy, M. Johnson, and V. Irudayaraj, The effect of extracts of Selaginella involvens and Selaginella inaequalifolia leaves on poultry pathogens, Asian Pacific Journal of Tropical Medicine, 3(9), 2010, 678-681.

9. M. Johnson, E.G. Wesely, M.I. Zahir Hussain, and Selvan N, In vivo and In vitro Phytochemical and anti-bacterial efficacy of Balisopermum montanum Muell. Arg, Asian Pacific Journal of Tropical Medicine, 3(11), 2010, 894-897.

10. R.D. Anpin Raja, S. Jeeva, J.W. Prakash, M. Johnson, and V. Irudayaraj, Antibacterial activity of selected ethnomedicinal plants from South India, Asian Pacific Journal of Tropical Medicine, 4(5), 2011, 375-378.

11. S. Jeeva, M. Johnson, J.S. Aparna, and V. Irudayaraj, Preliminary Phytochemical and Anti-bacterial studies on flowers of selected medicinal plants, Int J Med Arom Plants 1(2), 2011, 107-114.

12. Vimala Thankappan Anitha, M. Johnson, S. Jeeva, Anti-bacterial studies on Hemigraphis colorata (Blume) H.G. Hallier and Elephantopus scaber L., Asian Pacific Journal of Tropical Medicine, 5(1), 2012, 52-57.

13. T. Renisheya Joy Jeba Malar, S.L. Sushna, M. Johnson, N. Janakiraman, and T. Renola Joy Jeba Ethal, Bio-efficacy of the leaves extracts of Hyptis suaveolens (L.) Poit against the fish pathogens, International Journal of Life Science \& Pharma Science, 2(1), 2012, L128-L133.

14. T. Renisheya Joy Jeba Malar, M. Johnson, M. Mary Uthith, and A. Arthy, Antibacterial activity of ethanolic extracts of selected medicinal plants against human pathogens, Asian Pacific Journal of Tropical Biomedicine, 2011, S76-S78.

15. G. Szepesi, Some aspect of the validation of planar chromatographic methods used in pharmaceutical analysis, IGeneral principles and practical approaches, J Planar Chromatogr., 6, 1993, 187-189.

16. L.G. Korkina, Phenylpropanoids as naturally occurring antioxidants: from plant defense to human health, Cellular and Molecular Biology 53, 2007, 15-25.

17. Vincenzo Lattanzio, V.M.T. Lattanzio, and Angela Cardinali, Role of phenolics in the resistance mechanisms of plants against fungal pathogens and insects, Phytochemistry: Advances in Research, 2006, 23-67.

18. J.B. Harborne, Methods in Plant Biochemistry, Vol. 1 Plant Phenolics, P.M. Dey, and J.B. Harborne, (Eds.), Academic Press, London.

19. T. Vogt, Phenylpropanoid Biosynthesis, Molecular Plant, 3(1), 2010, 2-20.

20. J.M. Watt, and M.G. Breyer-Brandwijk, The Medicinal and Poisonous Plants of South and East Africa, Second Edition, Livingstone, Edinburgh, 1962.

21. Y.R. Chadha, (Ed.) The Wealth of India, Vol. 1. New Delhi, CSIR, Raw Materials, 1985.

22. R.S. Gupta, J.B. Kachhawa, and R. Chaudhary. Anti-fertility effects of methanolic pod extract of Albizia lebbeck Benth. in male rats, Asian J. Androl., 6(2), 2004, 155-159.

23. R.S. Gupta, R. Chaudhary, R.K. Yadav, S.K. Verma, and M.P. Dobhal, Effect of Saponins of Albizia lebbeck Benth. bark on the reproductive system of male albino rats, J. Ethnopharmacol., 96(1-2), 2005, 31-36. 
24. S.D. Chintawar, R.S. Somani, V.S. Kasture, and S.B. Kasture, Nootropic activity of Albizia lebbeck in mice, J. Ethnopharmacol., 81(3), 2002, 299-305.

25. N. Pratibha, V.S. Saxena, A. Amit, P. D'Souza, M. Bagchi, and D. Bagchi, Anti-inflammatory activities of Aller-7, a novel polyherbal formulation for allergic rhinitis, Int. J. Tissue. React., 26(1-2), 2004, 43-51.

26. C. Rahul, P. Pankaj, S.K. Sarwan, and J.K. Mahesh, Phytochemical screening and antimicrobial activity of Albizzia lebbeck, J. Chem. Pharm. Res., 2(5), 2010, 476-484.

27. B.B.S. Kapoor, Bhumika, and J.S. Khatri, Antimicrobial activity of some medicinal tree species of Hanumangarh district of Rajasthan, Journal of Phytological Research, 20, 2007, 325-326.

28. G. Carpani, F. Orsini, M. Sisti, and L. Verotta, Saponin forms Albizia antheimintica, Phytochemistry, 28, 1989, 863866.

29. F. Orsini, F. Pelizzoni, and L. Verotta. Saponins from Albizia lucida, Phytochemistry, 30(12), 1991, 4111-4115.

30. B.C. Pal, B. Achari, K. Yoshikawa, and S. Arihara, Saponins from Albizia lebbeck, Phytochemistry, 38(5), 1995, 1287-1291.

31. R.B. Rashid, R. Chowdhury, A. Jabbar, C.M. Hasan, and M.A. Rashid, Constituents of Albizia lebbeck and antibacterial activity of an isolated flavone derivatives, Saudi Pharm. J., 11(1-2), 2003, 52-56.

32. A.K. Barua, and S.P. Raman, The constitution of albigenic acid-A new triterpenoid sapogenin from Albizia lebbeck Benth, Tetrahedron, 7, 1959, 19-23.

33. A.M.D. El-Mousallamy, Leaf flavonoids of Albizia lebbeck, Phytochemistry, 48(4), 1998, 759-761.

34. M. Ueda, T. Tokunaga, M. Okazaki, N.U. Sata, K. Ueda, and S. Yamamura, Albiziahexoside: a potential source of bioactive saponin from the leaves of Albizzia lebbeck, Nat. Prod. Res., 17(5), 2003, 329-335.

35. L.N. Misra, A.K. Dixit, and H. Wagner, N-demethyl budmunchiamines from Albizia lebbeck seeds, Phytochemistry, 39(1), 1995, 247-249.

36. Y.T. Maa, S.C. Hsiaob, H.F. Chenb, and F.L. Hsu, Tannins from Albizia lebbeck, Phytochemistry, 46(8), 1997, $1451-$ 1452.

37. M.D. Nazneen Bobby, E.G. Wesely, and M. Johnson, High performance thin layer chromatography profile studies on the alkaloids of Albizia lebbeck, Asian Pacific Journal of Tropical Biomedicine, 2012, 1-6.

38. J.B. Harborne, Phytochemical methods, 3rd ed., London: Chapman and Hall, 1998.

39. H. Wagner, S. Baldt, and E.M. Zgainski, Plant Drug Analysis, Berlin: Springer, 1996.

40. P.J. Facchini, Alkaloid biosynthesis in plants: Biochemistry, cell biology, molecular regulation and metabolic engineering, Апnи. Rev. Plant Physiol. Plant Mol. Biol., 52, 2001, 29-66.

41. S.A. Holstein, and R.J. Hohl, Isoprenoids: Remarkable diversity of form and function, Lipids, 34, 2004, 293-309.

42. M. Iriti, and F. Faoro, Plant defense and human nutrition: the phenylpropanoids on the menu, Curr. Top. Nutrac. Res., 2, 2004, 47-95.

43. R.A. Dixon, and N.L. Paiva, Stress-induced phenylpropanoid metabolism. Plant Cell, 7, 1995, 1085-1097.

44. C.J. Douglas, Phenylpropanoid metabolism and lignin biosynthesis: from weeds to trees, Trends in Plant Science, 1, 1996, 171-178.

45. P. Barmejo, M.J. Abad, A.M. Diaz, L. Fernandez, J.D. Santos, S. Sanchez, L. Villaescusa, L. Carrasco, and A. Irurzun, Antiviral activity of seven iridoids, three saikosaponins and one phenylpropanoid glycoside extracted from Bupleurum rigidum and Scrophularia scorodonia, Planta Med., 68, 2002, 106-110.

46. F. Ververidis, E. Trantas, C. Douglas, G. Vollmer, G. Kretzschmar, and N. Panopoulos, Biotechnology of flavonoids and other phenylpropanoid-derived natural products, Part I: Chemical diversity, impacts on plant biology and human health, Biotechnol J., 2(10), 2007, 1214-1234.

47. M. Yamunadevi, E.G. Wesely, and M. Johnson, Chromatographic fingerprint analysis on flavonoids constituents of the medicinally important plant Aerva lanata L. by HPTLC technique, Asian Pacific Journal of Tropical Biomedicine, 2012, S8-S12.

48. M. Yamunadevi, E.G. Wesely, and M. Johnson, Chromatographic finger print analysis of steroids in Aerva lanata L by HPTLC technique, Asian Pacific Journal of Tropical Biomedicine, 2011, 428-433.

49. M. Yamunadevi, E.G. Wesely, and M. Johnson, Chemical Profile Studies on the Alkaloids of medicinally important plant Aerva lanata L. using HPTLC, Journal of Natura Conscientia, 2(2), 2011, 341-349. 
50. M. Yamunadevi, E.G. Wesely, and M. Johnson, A Chromatographic Study on the Glycosides of Aerva lanata L, Chinese Journal of Natural Medicines, 9(3), 2011, 210-214.

51. A.K. Tripathi, R.K. Verma, A.K. Gupta, M.M. Gupta, and S.P.S. Khanuja, Quantitative Determination of Phyllanthin and Hypophyllanthin in Phyllanthus Species by High-performance Thin Layer Chromatography, Phytochem. Anal., 17, 2006, 394-397.

52. V. Ramya, V. Dheena Dhayalan, and S. Umamaheswari, In vitro studies on antibacterial activity and separation of active compounds of selected flower extracts by HPTLC, J. Chem. Pharm. Res., 2(6), 2010, 86-91.

53. A.G. Patil, S.P. Koli, D.A. Patil, and N. Chandra, Phamacognostical standardization and HPTLC finger print of Crataeva tapia Linn. SSP. Odora [Jacob.] Almeida leaves, International Journal of Pharma and Biosciences, 1(2), 2010, 1-14.

54. S.U. Rakesh, V.R. Salunkhe, P.N. Dhabale, and K.B. Burade, HPTLC Method for Quantitative Determination of Gallic Acid in Hydroalcoholic Extract of Dried Flowers of Nymphaea stellata Willd., Asian J. Research Chem., 2(2), 2009, 131-134.

55. S.U. Rakesh, P.R. Patil, V.R. Salunkhe, P.N. Dhabale, and K.B. Burade, HPTLC method for quantitative determination of quercetin in hydroalcoholic extract of dried flower of Nymphaea stellata willd., International Journal of Chem Tech Research, 1(4), 2009, 931-936.

56. V. Sharma, N. Sharma, B. Singh, and R.C. Gupta, Cytomorphological studies and HPTLC fingerprinting in different plant parts of three wild morphotypes of Datura metel L. "Thorn Apple" from North India, Int J Green Pharm, 3, 2009, 40-46. 
Table - 1: HPTLC - Phenyl propanoid profile of the Petroleum Ether (A) extracts of Albizia lebback

\begin{tabular}{|c|c|c|c|c|}
\hline Peak & $\mathbf{R f}$ & Height & Area & Assigned substance \\
\hline 1 & 0.02 & 411.7 & 4870.6 & Unknown \\
\hline 2 & 0.18 & 430.2 & 10296.0 & Unknown \\
\hline 3 & 0.33 & 199.8 & 7720.3 & Unknown \\
\hline 4 & 0.40 & 103.8 & 3179.5 & Unknown \\
\hline 5 & 0.44 & 101.8 & 2726.7 & Unknown \\
\hline 6 & 0.48 & 166.7 & 5016.4 & Phenyl propanoid 1 \\
\hline 7 & 0.53 & 58.2 & 1237.1 & Unknown \\
\hline 8 & 0.62 & 60.7 & 1419.6 & Unknown \\
\hline 9 & 0.66 & 101.0 & 1814.0 & Unknown \\
\hline 10 & 0.67 & 88.1 & 2265.5 & Unknown \\
\hline 11 & 0.74 & 52.1 & 959.1 & Unknown \\
\hline 12 & 0.83 & 32.2 & 695.1 & Phenyl propanoid 2 \\
\hline 13 & 0.92 & 27.4 & 658.2 & Unknown \\
\hline
\end{tabular}

Table - 2: HPTLC - Phenyl propanoid profile of the Methanolic extracts (B) of Albizia lebback

\begin{tabular}{|c|c|c|c|c|}
\hline Peak & Rf & Height & Area & Assigned substance \\
\hline 1 & 0.02 & 24.0 & 171.3 & Unknown \\
\hline 2 & 0.18 & 12.1 & 197.9 & Unknown \\
\hline 3 & 0.32 & 61.9 & 1438.1 & Unknown \\
\hline 4 & 0.34 & 44.9 & 993.6 & Unknown \\
\hline 5 & 0.76 & 20.1 & 236.4 & Unknown \\
\hline 6 & 0.94 & 65.6 & 708.0 & Unknown \\
\hline
\end{tabular}


IOSR Journal of Pharmacy

Vol. 2, Issue 1, Jan-Feb.2012, pp. 030-040

Table - 3: HPTLC - Phenyl propanoid profile of the Ethyl acetate (C) extracts of Albizia lebback

\begin{tabular}{|c|c|c|c|c|}
\hline Peak & Rf & Height & Area & Assigned substance \\
\hline 1 & 0.01 & 50.5 & 206.5 & Unknown \\
\hline 2 & 0.14 & 26.2 & 383.5 & Unknown \\
\hline 3 & 0.18 & 51.5 & 992.8 & Unknown \\
\hline 4 & 0.26 & 40.1 & 845.3 & Unknown \\
\hline 5 & 0.32 & 243.2 & 7860.6 & Unknown \\
\hline 6 & 0.40 & 45.5 & 742.6 & Unknown \\
\hline 7 & 0.47 & 43.9 & 1327.3 & Unknown \\
\hline 8 & 0.56 & 51.5 & 1384.6 & Unknown \\
\hline 9 & 0.60 & 33.5 & 452.1 & Unknown \\
\hline 10 & 0.62 & 51.4 & 417.0 & Unknown \\
\hline 11 & 0.66 & 46.2 & 1473.9 & Unknown \\
\hline 12 & 0.77 & 11.5 & 122.4 & Unknown \\
\hline 13 & 0.91 & 19.0 & 318.4 & Unknown \\
\hline 14 & 0.94 & 18.8 & 272.4 & Unknown \\
\hline
\end{tabular}


IOSR Journal of Pharmacy

Vol. 2, Issue 1, Jan-Feb.2012, pp. 030-040

Table - 4: HPTLC - Phenyl propanoid profile of Albizia lebback Leaves Extracts

\begin{tabular}{|c|c|c|c|}
\hline Rf & $\begin{array}{c}\text { Petroleum } \\
\text { ether }(\mathrm{A})\end{array}$ & $\begin{array}{l}\text { Methanol } \\
\text { (B) }\end{array}$ & $\begin{array}{c}\text { Ethyl acetate } \\
\text { (C) }\end{array}$ \\
\hline 0.01 & & & + \\
\hline 0.02 & + & + & \\
\hline 0.14 & & & + \\
\hline 0.18 & + & + & + \\
\hline 0.26 & & & + \\
\hline 0.32 & & + & + \\
\hline 0.33 & + & & \\
\hline 0.34 & & + & \\
\hline 0.4 & + & & + \\
\hline 0.44 & + & & \\
\hline 0.47 & & & + \\
\hline 0.48 & + & & \\
\hline 0.53 & + & & \\
\hline 0.56 & & & + \\
\hline 0.6 & 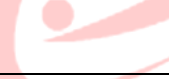 & & + \\
\hline 0.62 & + & & + \\
\hline 0.66 & + & & + \\
\hline 0.67 & + & & \\
\hline 0.74 & + & & \\
\hline 0.76 & & + & \\
\hline 0.77 & & & + \\
\hline 0.83 & + & & \\
\hline 0.91 & & & + \\
\hline 0.92 & + & & \\
\hline 0.94 & & + & + \\
\hline
\end{tabular}


IOSR Journal of Pharmacy

Vol. 2, Issue 1, Jan-Feb.2012, pp. 030-040
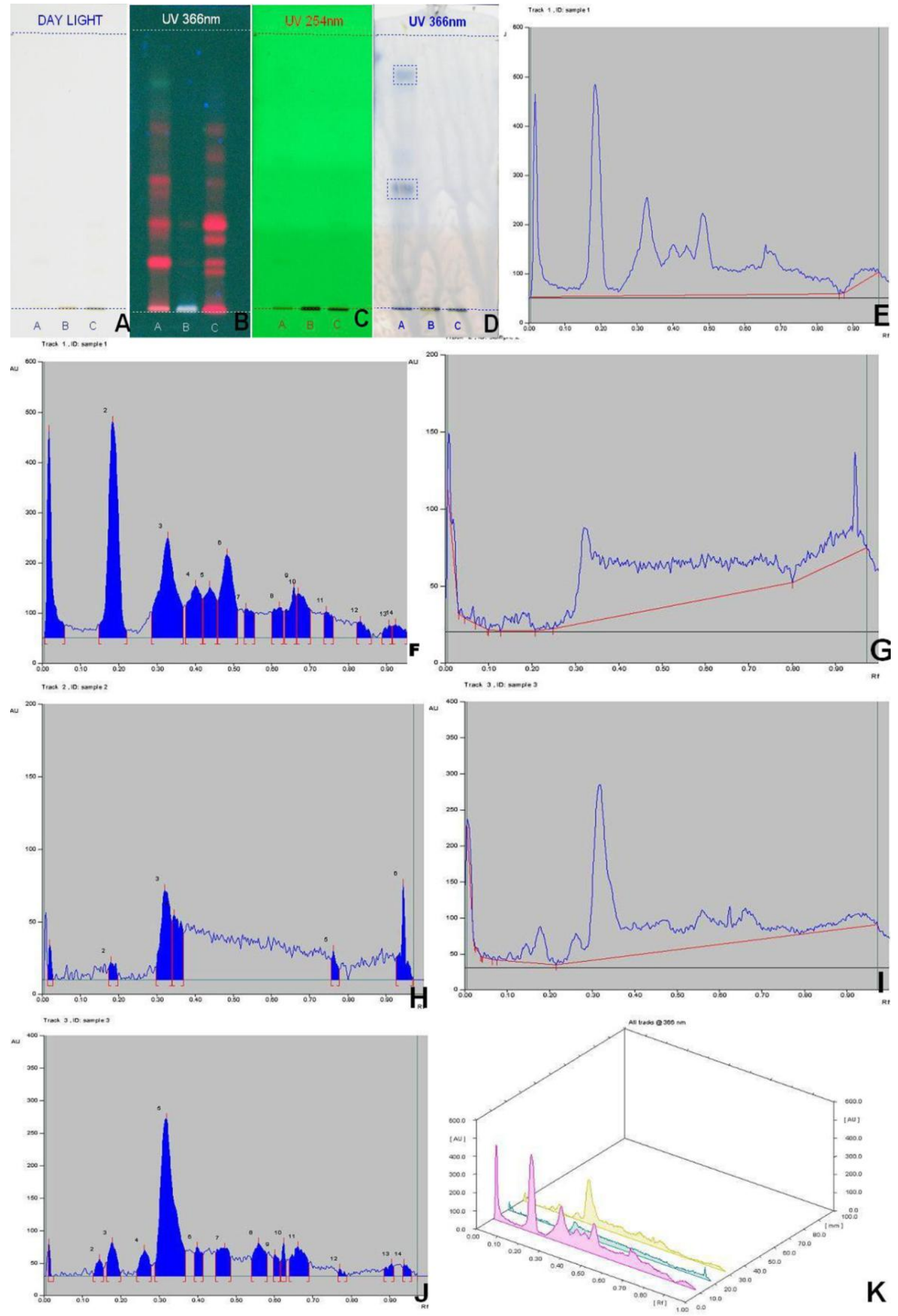

Fig. 1. HPTLC Profile and Chromatogram of Albizia lebbeck. 

A. HPTLC profile of the Albizia lebbeck under Daylight
B. HPTLC profile of the Albizia lebbeck under UV 366
C. HPTLC profile of the Albizia lebbeck under UV 254
D. HPTLC profile of the Albizia lebbeck under Day Light - After Derivation
E. HPTLC Chromatogram of Petroleum ether extracts of Albizia lebbeck - Baseline display - Scanned at $366 \mathrm{~nm}$
F. HPTLC Chromatogram of Petroleum ether extracts of Albizia lebbeck - Peak densitogram display - Scanned at $366 \mathrm{~nm}$
G. HPTLC Chromatogram of Methanolic extracts of Albizia lebbeck - Baseline display - Scanned at $366 \mathrm{~nm}$
H. HPTLC Chromatogram of Methanolic extracts of Albizia lebbeck - Peak densitogram display - Scanned at 366 $\mathrm{nm}$
I. HPTLC Chromatogram of Ethyl acetate extracts of Albizia lebbeck - Baseline display - Scanned at $366 \mathrm{~nm}$
J. HPTLC Chromatogram of Ethyl acetate extracts of Albizia lebbeck - Peak densitogram display - Scanned at 366 $\mathrm{nm}$
K. 3D display of HPTLC Chromatogram of Albizia lebbeck - Petroleum ether, methanolic and ethyl acetate leaves extracts of Albizia lebbeck 